\title{
Organization Culture of Safety-Comparison of Two Periods, before and after Intervention
}

\section{Niv $\mathrm{Y}^{1,2 *}$ and Zetland $\mathrm{R}^{2}$}

${ }^{1}$ Department of Quality and Patient safety, Tel Aviv University, Israel

${ }^{2}$ Rabin Medical Center, Clalit Health Services, Israel

*Corresponding author: Yaron Niv, Department of Quality and Patient safety, Tel Aviv University, Ministry of Health, 39 Yirmiyahu Street, Jerusalem, Israel, Tel: 972-2-5080313 \& 972-50-6242098, Fax: 972-2-5655962; Email: yaron.niv@moh.gov.il; nivyaron80@gmail.com

\section{Research Article}

Volume 3 Issue 2

Received Date: March 06, 2020

Published Date: April 06, 2020

DOI: $10.23880 /$ jqhe-16000154

\section{Abstract}

Background: Since 1999, when the Institute of Medicine declared that "To err is human" and recommended to avoid "blaming and shaming", our culture of safety changed tremendously. Nowadays we try to investigate errors and adverse events, to learn from mistakes, and prevent future sentinel events and patients' suffering.

Objective: The aim of our study is to assess the change in staff members' attitude towards the hospital culture of safety in 2017 in comparison to 2015, and to associate this attitude to improvement in quality indicators and reports of "near miss" cases.

Methods: A questionnaire was introduced to staff members in Rabin Medical Center in 2015, and in 2017 after an intervention. We compared the results looking for change in staff members' attitude towards patient's safety. We also compared the results of quality indicators and number of adverse events reported before and after the intervention.

Results: Comparing the results of the questionnaires there is a significant improvement in 13 out of 15 items. The RR was 1.555 with 95\%CI 1.370-1.766 ( $\mathrm{P}<0.0001)$. The differences were statistically significant in 7 items and with a trend in 2 items. Comparing the performance of the quality indicators there is also a significant improvement in 18 out of 24 measures. The RR was 1.236 with 95\%CI 1.220-1.253 $(\mathrm{P}<0.0001)$. The differences were statistically significant in 10 indicators and with a trend in 2 indicators.

Conclusions: We believe that quality improvement plans will really change the staff approach and behavior towards a better safety culture in the hospital.

Keywords: Culture of Safety; Patient Safety; Risk Management; Quality Assurance; Hospital Safety

Abbreviations: RCA: Root Cause Analysis; RMC: Rabin Medical Center; PE: Pulmonary Emboli; FMEA: Failure Mode and Effect Analysis; ISBAR: Introduction, Situation, Background, Assessment, Recommendation; PCI: Percutaneous Coronary Intervention; STEMI: ST Elevation Myocardial Infarction; TPA: Tissue Plasminogen Activator; CVA: Cerebro Vascular Accident; PDCA = Plan, Do, Check, Act; TIA: Transient Ischemic Attack; DVT: deep vein thrombosis.

\section{Introduction}

Since 1999, when the Institute of Medicine declared that "to err is human" and recommended to avoid "blaming and shaming", our culture of safety changed tremendously [1]. Nowadays we try to investigate errors and adverse events, to learn from our mistakes, and prevent future sentinel events and patients' suffering. There is a significant advance in patients' safety in hospitals all over the world. Quality 
and safety indicators of processes and outcome are very popular and help us keep the high level of treatment quality and safety. Hospitals' accreditation by international institute (such as the JCI), regular investigations, check lists before operations and important invasive procedure, measuring quality indicators and annual quality improvement plans, helped medical centers to achieve high level of safety and prevented many preventable deaths $[2,3]$.

In 2015 a questionnaire regarding staff positions and knowledge of patients' safety culture in Israeli hospitals was circulated by the Ministry of Health. The questionnaire was based on a Canadian paper [4], and was offered to employees (physicians, nurses and other health workers) in every public general hospital. Very few staff members in our hospital answered the questionnaire. Four main issues were addressed: the understanding of patient's safety, the attitude of the direct manager to safety problems, the number of reporting and communication.

After an intervention and intensive quality improvement plan we repeated the questionnaire in our medical center. This time we approached 1000 employees, and had compliance of 641 participants.

The aim of our study is to assess the change in staff members' attitude towards the hospital culture of safety in 2017 compared to 2015, and to associate this attitude to improvement in quality indicators and reports regarding adverse events and near miss cases.

\section{Methods}

We used Can-PSCS [4] (previously called the Patient
Safety Culture Tool) data collected from staff in a large, crosssectional sample of Canadian healthcare organizations. Survey data was collected in 2011 by Accreditation Canada as part of the Qmentum accreditation programme [5].

A questionnaire of 15 items was introduced to 500 staff members in Rabin Medical Center in 2015. After an intervention plan performed in 2016, the same questionnaire was introduced to 1000 staff members in 2017. We compared the results of the questionnaires of 2015 and 2017 looking for change in staff members' attitude towards patient's safety in the medical center. We also compared the results of quality indicators and number of adverse events reported before and after the intervention.

\section{Intervention (Quality Improvement Plan)}

In the year 2016 a quality intervention plan was established, focusing on patient safety, and prepared according the JCI requirements (JCI accreditation version $5^{\text {th }}$ ) [2]. During this year 5 Quality and Inspection Committees, 3 failure mode and effects analysis (FMEA) and 13 root cause analysis (RCA) processes were done, 5 issues of the management target were selected, 5 clinical protocols for all the departments were chosen, and 25 safety rounds were done (Table 1). Every department was asked to choose a specific clinical protocol in the plan, do, check, act (PDCA) method for improvement, dealing with care givers communication, optimization of treatment of acute diseases, equilibration of treatment in chronic diseases, prevention of therapy complication and safety and prevention of clinical failures, all with quality indicators (Table 2).

\begin{tabular}{|c|l|}
\hline \multicolumn{1}{|c|}{ Intervention } & \multicolumn{1}{|c|}{ Details } \\
\hline \multirow{4}{*}{ Quality and Inspection Committees } & 1. Treatment outcome in RMC \\
\cline { 2 - 2 } & 2. Resuscitation processes \\
\cline { 2 - 2 } & 3. Medication reconciliation \\
\cline { 2 - 2 } & 4. Prevention of DVT and PE \\
\cline { 2 - 2 } & 5. Failures in identifying patients in the radiology department \\
\hline \multirow{2}{*}{ FMEA processes } & 1. Prevention of newborn falls \\
\cline { 2 - 2 } & 2. Giving medical consultation between departments \\
\cline { 2 - 2 } & 3. Transfer of the critically ill patients \\
\hline \multirow{2}{*}{ RCA processes } & 13 processes for sentinel events \\
\hline \multirow{2}{*}{ Issues in the management target } & 1. preparation for fire \\
\cline { 2 - 2 } & 2. ISBAR - communication tool \\
\cline { 2 - 2 } & 3. Hand hygiene \\
\cline { 2 - 2 } & 4. Prevention of pressure sores \\
\cline { 2 - 2 } & 5. Reports of medication side effects \\
\hline
\end{tabular}




\begin{tabular}{|l|l|}
\hline \multirow{4}{*}{ Clinical protocols } & 1. PCI within 90 minutes of STEMI in \\
\cline { 2 - 2 } & the emergency department \\
\cline { 2 - 2 } & 2. Prevention of DVT \\
\cline { 2 - 3 } & 3. Treatment with TPA for acute CVA \\
\cline { 2 - 3 } & in the emergency department \\
\cline { 2 - 3 } & 4. Treatment of pain after surgery \\
\cline { 2 - 3 } & 5. Diabetes Mellitus equilibration \\
\hline Safety rounds in the departments & 25 in 2016 \\
\hline
\end{tabular}

RMC: Rabin Medical Center; DVT: Deep Vein Thrombosis; PE: Pulmonary Emboli; FMEA: Failure Mode and Effect Analysis; ISBAR: Introduction, Situation, Background, Assessment, Recommendation; PCI: Percutaneous Coronary Intervention; STEMI: ST Elevation Myocardial Infarction; TPA: Tissue Plasminogen Activation; CVA: Cerebro Vascular Accident

Table 1: Quality Intervention Plan for 2016.

\begin{tabular}{|c|c|}
\hline Department & Protocol \\
\hline Internal Medicine A & Prevention of pressure sores \\
\hline Internal Medicine B & Diabetes Mellitus equilibration \\
\hline Internal Medicine C & Treatment of pain \\
\hline Internal Medicine D & Prevention of pressure sores \\
\hline Internal Medicine E & Prevention of pressure sores \\
\hline Geriatrics & Reports of medication side effects and adverse events \\
\hline Orthopedics Surgery & Prevention of pressure sores \\
\hline Vascular Surgery & Diabetes Mellitus equilibration \\
\hline Surgery B & Prevention of infections in the intensive care unit \\
\hline Neurosurgery & Nurse escort of patients for the operating room to prevent failures in patients delivery \\
\hline Urology & Telephonic survey of patients using self-catheterization \\
\hline Gynecology & Prevention of failures in the delivery room \\
\hline Physiotherapy & Sphincters control \\
\hline Management & Prevention of fire threat \\
\hline Radiology & Key image \\
\hline Chest Surgery & Cell saver \\
\hline
\end{tabular}

PDCA = Plan, Do, Check, Act

Table 2: Clinical protocols of the hospital departments, PDCA system.

New computerized tools were developed for daily management and follow up of activity and quality indicators. Direct investigation was started after mortality, length of hospitalization, re-hospitalization, recurrent visits to the emergency department, re-operations, and mortality within 30 days of hospitalization. A follow up plan for continuation of treatment between the hospital and the community was established.

A comprehensive educational plan was practiced during the year, dealing with all the aspects of the quality plan and the hospital risk management such as adverse events and "near miss" reports, investigations of adverse events, safety rounds, and preparation for inspections, claims and prevention of complaints. In 2016 the members of the quality and safety department attended all the departments' staff meetings (150 meetings) and 3 staff meetings dealing with quality and safety were performed for the whole hospital staff. We assumed that all this activity would influence the staff members' approach and principles regarding the hospital culture of safety.

\section{Results}

The results of both questionnaires, 2015 and 2017, 
are shown in Figure 1. The compliance was much better in 2017 than in 2015, 64.1\% versus 20.6\%, respectively $\mathrm{P}<0.001$. In 2017 only $33 \%$ of the participants believe that there are patient's safety problems in their unit, and only $14 \%$ think that only by chance more severe adverse events do not happen. The vast majority believes that staff members behave with dignity and respect to each other and that they learn from their mistakes and act on a daily basis to prevent future mistake as well. Eighty-one percent think that their superior does not ignore safety issues, 73\% think that the manager seriously considers staff suggestions for the improving patient safety, and $60 \%$ testify that their superior them on a job well done, according to an established patient safety procedure. Thirty eight percent of the participants reported "near miss" cases in the last year, 3.8 in average per employee, and 69\% said that a "near miss" is always reported; $76 \%$ said that they have "no blame nor shame" policy in their department and an atmosphere that encourage reporting adverse events and "near miss" events, and only $16 \%$ thought that after reporting the staff member is blamed, instead of looking for system fault. Eighty percent declared that staff will freely speak up if they see something that may negatively affect patient safety, and $62 \%$ thought that a staff member will freely speak up if they see a wrong decision made by their superior.

Comparing the results of the questionnaires between 2015 to 2017 there is a significant improvement in 13 out of 15 items. In only 2 items the questionnaire of 2015 had better results than 2017, but the results were not statistically significant (Figure 1). The RR of 2017 versus 2015 was 1.555 with $95 \%$ CI $1.370-1.766(\mathrm{P}<0.0001)$. The differences were statistically significant in 7 items and with a trend for significance in 2 items.

\section{Culture of safety, 2015 versus 2017}

$\underline{\text { Surk name }}$

In our unit people treat each other withrespect

We are actively doing things to improve patient safety

Mistakes have led to positive changes here

It is just by chance that more serious mistakes do no happen- negative answer

Noblame and shame policy

My manager says a good word when he/she sees a job done according to established patient safety procedures

My manager seriously consider staff suggestions for improving patient safety

My manager overlookpatient safety issues - negative answer

In our unit there is open communication about patient safety

In our unit there is atmosphere that encourages reporting adverse events and near miss events

We have patient safety problems in our unit - negative answer

Staff will freely speakup if they see something that may negatively affect patient safety

Staff will freely speakup if they see wrong decision of their superior

Near miss events are reported

Average number of event reports in the last 24 months $>6$

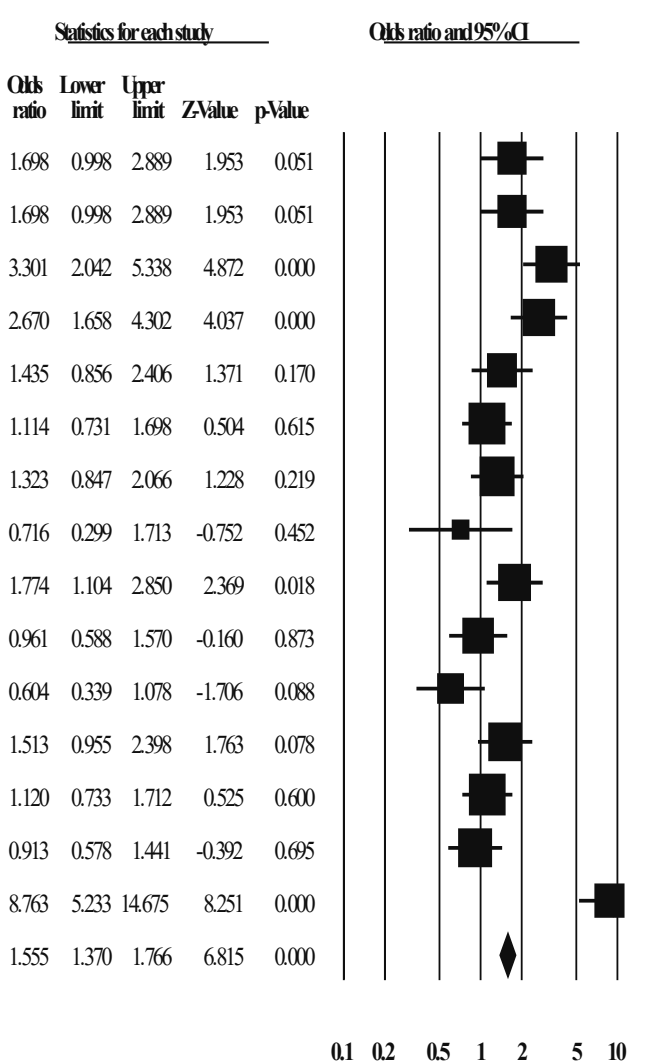

Favours 2015 Favours 2017

Figure 1: Results of the safety culture survey 2015, 2017 (RR and 95\%CI). 
Comparing the performance of the quality indicators between 2015 to 2016 there is also a significant improvement in 18 out of 24 measures. In only 6 indicators the performance was better in 2015 that reach significance in only 1 (Figure
2). The RR of 2016 versus 2015 was 1.236 with $95 \% \mathrm{CI}$ 1.220-1.253 $(\mathrm{P}<0.0001)$. The differences were statistically significant in 10 indicators and with a trend for significance in 2 indicators.

\section{Performance of quality indicators, 2015 versus 2016}

$\underline{\text { Study name }}$

Primary PC vithin 90 min in STEM

Aspirin after MI

TPA in Stroke within 3h

Duplex in TIA within $72 \mathrm{~h}$

DVT Risk Assessment in internal medicine dep.

Prophylactic antibiotics before Colectomy

Longer hospitalization (>8d) following Colectomy for CRC

Femoral neck fracture operated within $48 \mathrm{~h}$

Antibiotics before Femoral neck fracture operated

TURP - readmissions within 2 week

RE-hospitalization within two weeks after Gynecologic elective surgery

RE-hospitalization within two weeks after Cesarean elective surgery

Preventive antibiotic treatment in Cesarean surgery

Preventive anti- thrombotic treatment in Hysterectomy

Chest $\mathrm{x}$-rays Interpretation

CT/MRI in CVA within 25 min

CLABS for 1,000 catheter-days

Costridium difficile incidence for 1,000 hospitalization day

Readmissions to ER Within 48h

Computering diagnosis in the ED

Falls

Planned Discharge

Reducing chest $\mathrm{x}$-rays before elective surgery

Computering main diagnosis in the Chameleon
Statistics for each study

Odds ratio and $95 \% \mathrm{CI}$

Odds Lower Upper

ratio limit limit Z-Value $p$-Value

$\begin{array}{lllll}1.071 & 0.633 & 1.812 & 0.254 & 0.800\end{array}$

$\begin{array}{lllll}0.413 & 0.131 & 1.304 & -1.507 & 0.132\end{array}$

$\begin{array}{lllll}0.966 & 0.578 & 1.615 & -0.130 & 0.896\end{array}$

$\begin{array}{llllll}6.570 & 4.821 & 8.953 & 11.922 & 0.000\end{array}$

$\begin{array}{llllll}1.451 & 1.364 & 1.542 & 11.892 & 0.000\end{array}$

$\begin{array}{llllll}0.573 & 0.312 & 1.052 & -1.796 & 0.072\end{array}$

$\begin{array}{lllll}1.104 & 0.711 & 1.714 & 0.439 & 0.661\end{array}$

$\begin{array}{llllll}1.130 & 0.733 & 1.741 & 0.553 & 0.580\end{array}$

$\begin{array}{llllll}1.631 & 0.934 & 2.846 & 1.721 & 0.085\end{array}$

$\begin{array}{llllll}1.434 & 0.509 & 4.038 & 0.682 & 0.495\end{array}$

$\begin{array}{llllll}1.571 & 0.709 & 3.482 & 1.113 & 0.266\end{array}$

$\begin{array}{llllll}1.152 & 0.430 & 3.085 & 0.282 & 0.778\end{array}$

$\begin{array}{lllll}2.104 & 1.703 & 2.601 & 6.882 & 0.000\end{array}$

$\begin{array}{lllll}3.963 & 2.151 & 7.300 & 4.417 & 0.000\end{array}$

$\begin{array}{lllll}1.044 & 1.017 & 1.070 & 3.298 & 0.001\end{array}$

$\begin{array}{llllll}3.755 & 2.317 & 6.086 & 5.370 & 0.000\end{array}$

$\begin{array}{lllll}3.643 & 0.438 & 30.287 & 1.197 & 0.231\end{array}$

$\begin{array}{llll}0.849 & 0.661 & 1.091 & -1.282\end{array}$

$\begin{array}{llll}1.972 & 1.762 & 2.206 & 11.840\end{array}$

$\begin{array}{llll}1.084 & 1.051 & 1.118 & 5.131\end{array}$

$\begin{array}{lllll}0.832 & 0.730 & 0.949 & -2.744\end{array}$

$\begin{array}{lllll}1.395 & 1.337 & 1.455 & 15.386\end{array}$

$\begin{array}{lllll}0.976 & 0.847 & 1.125 & -0.335\end{array}$

$\begin{array}{llll}1.420 & 1.387 & 1.453 & 29.843\end{array}$

$\begin{array}{llll}1.236 & 1.220 & 1.253 & 31.055\end{array}$

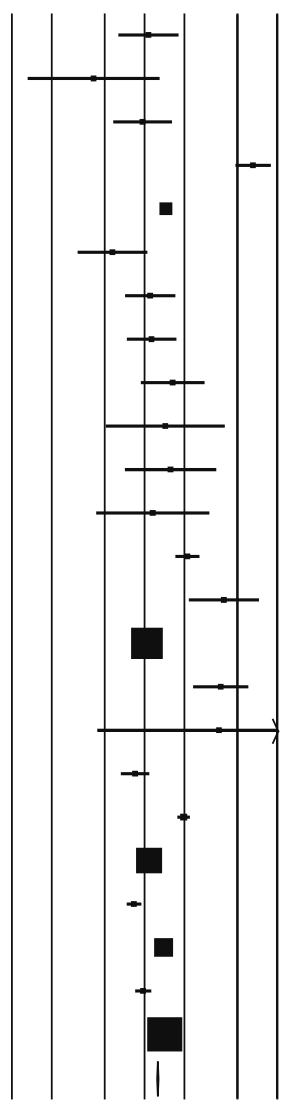

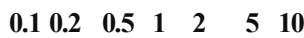

Favours $2015 \quad$ Favours 2016

Figure 2: Performance of the quality indicators 2015, 2016 (RR and 95\%CI).

\section{Discussion}

When getting the results of our safety culture survey in 2015, measuring providers' perceptions across our health settings, we were very disappointed, even though our results were very similar to other hospitals in Israel with no significant differences. Yet, we thought that the small number of participants and the very low compliance, do not allow a meaningful interpretation of this important questionnaire.

Following the survey of 2015 we performed a comprehensive quality intervention project and repeated the questionnaire in 2017. This time the compliance was much higher as were the improvement in the staff perceptions 
regarding safety climate and interpretation of the health providers regarding safety issues.

Ginsburg LR, et al. [4] confirm the validity of the Can-PSCS in a comprehensive study, initial and cross-validation samples of 13126 and 6324 direct care providers from 119 and 35 health settings across Canada, respectively. They described 6 dimensions of patient's safety: organizational leadership support, incident follow-up, supervisory leadership, unit learning culture, enabling open communication, judgmentfree environment and enabling open communication.

It is no easy or feasible to claim that our proactive activity changed the opinions of our staff, physicians, nurse, pharmacists, secretaries and other people involved in patients care. Yet, we also found a significant improvement in almost every measure that directly related to the safety culture. For example most of the quality indicators and "near miss" reports were significantly improved. It's possible that engaging in all of the changes mentioned might have led to real changes in the answers to the survey questions. But, with such a large change in the response rate, it's also just as likely that the different pattern reflects inclusion of a broader range of staff. Sometimes one likes to argue that the people with better attitudes are usually the ones who respond to surveys, but it can also be that the unhappy staff wants to express their unhappiness. It's hard to know. So, the paper does not work well as a robust demonstration of an intervention that improves culture-it's too hard to know if the results represent real improvement or just reaching a broader population of staff.

The relationship between intervention and improvement in medicine has been an issue for debate for many years [6,7]. The correlation between process and outcome is not always clear, and sometimes can be misleading. We use many quality indicators of process such as duplex in transient ischemic attack (TIA), deep vein thrombosis (DVT) risk assessment, and prophylactic antibiotics before colectomy, without assessing outcome of TIA, DVT or colectomy in our hospital, relying on the literature benchmark that might be very different in our hospital or community. We are not the first to find a positive correlation between change in the culture of safety and staff attitude and better outcome of quality measures. Haynes $\mathrm{AB}$ et al demonstrated significant changes in safety attitude and relationship to decreased postoperative morbidity and mortality following implementation of a checklist-based surgical safety intervention [8]. Thus, we believe that quality improvement plans will really change the staff approach and behavior towards a better safety culture in the hospital.

\section{Conflict of Interest}

The authors disclose no conflicts

\section{References}

1. www.nationalacademies.org/hmd/ /media/Files/ Report\%20Files/1999/To-Erris-Human/To\%20 Err\%20is\%20Human\%201999\%20\%20report\%20 brief.pdf

2. Cohen A, Dreiher J, Regev Rosenberg S (2010) A quality control program for Clalit Health Services: the first decade. Harefuah 149: 1-6.

3. Chassin M, Loeb JM, Schmaltz SP, Wachter RM (2010) Accountability measures-using measurement to promote quality improvement. N Engl J Med 383: 683688.

4. Ginsburg LR, Tregunno D, Norton PG (2014) Not another safety culture survey: using the Canadian patient safety climate survey (Can-PSCS) to measure provider perceptions of PSC across health settings. BMJ Qual Saf 23(2): 162-170.

5. Mitchell JI, Nicklin W, MacDonald B (2012) The determinants of quality healthcare: Implications for Canadian health leaders. Healthc Manag Forum 25(3): 138-141.

6. Thomson H, Thomas S, Sellstrom E, Petticrew M (2009) The health impacts of housing improvement: a systematic review of intervention studies from 1887 to 2007. Am J Public Health 99(S3): S681-692.

7. Crocker JB, Crocker JT, Greenwald JL (2012) Telephone follow-up as a primary care intervention for post discharge outcomes improvement: a systematic review. Am J Med 125(9): 915-21.

8. Haynes AB, Weiser TG, Berry WR (2011) Changes in safety attitude and relationship to decreased post-operative morbidity and mortality following implementation of a checklist-based surgical safety intervention. BMJ Qual Saf 20(1): 102-107. 